\title{
Analysis of genotype-by-environment interaction in winter wheat growth in organic production system
}

\author{
Osval Antonio Montesinos-López ${ }^{1 *}$, P. Stephen Baenziger², Kent M. Eskridge³, Richard S. Little², \\ Eliel Martínez-Crúz ${ }^{4}$, Emeterio Franco-Perez ${ }^{5 *}$
}

${ }^{1}$ Faculty of Telematics, University of Colima. Av. Universidad 333, Col. Las Víboras, C.P. 28040, Colima, México, ${ }^{2}$ Department of Agronomy and Horticulture, University of Nebraska, Lincoln, Nebraska, USA, ${ }^{3}$ Department of Statistics, University of Nebraska, Lincoln, Nebraska, USA, ${ }^{4}$ Wheat Program. National Institute for Forestry, Agriculture and Animal Research. Valle de México Experiment Station. 56250. Coatlinchán, Texcoco, Estado de México, ${ }^{5}$ Faculty of Marketing, University of Colima. Av. Universidad 333, Col. Las Víboras, C.P. 28040, Colima, México

\section{A B S T R A C T}

The goal of this study was to evaluate the performance of 36 wheat winter (Triticum aestivum L.) lines in organic systems in three locations in Nebraska, to compare the performance of the released cultivars with experimental lines to help in the process of selection, to study the magnitude and behavior of genotype-by-environment interaction for grain yield, anthesis date, plant height, protein content, grain volume weight and vegetation index, and to identify the more stable genotypes. Linear mixed models and site regression model was implemented for reaching the objectives of the present research. Genotypic and GE interaction are significant across the three locations for all traits except for anthesis date. Environment were significant for the six traits. Yield is negative correlated with protein content and plant height. In general the genetic correlation explained more of the genotype performance, although the GE interaction was significant. The best genotypes for grain yield across the three environments were genotypes NW03666, SD07165, NE07444 and Overland. For vegetation index the best lines were: Lyman and Buckskin. For grain volume weight the best lines were: Lyman, NW03681, Danby and Goodstreak. For anthesis date all genotypes were similar. For plant height, the best lines were Goodstreak, Buckskin and Clarkscream. For protein content, the best lines were Goodstreak, Karl92, Lyman, and Clarkscream. In general the average grain yield of the experimental lines was better than the released lines. For anthesis date, the performance was similar between experimental and released lines. However, for vegetation index, plant height, grain volume weight and protein content, the average performance of the experimental lines was lower than the released lines.

Keywords: Triticum aestivum L.; Yield, Protein; Genotype x environment interaction; Stability

\section{INTRODUCTION}

Wheat (Triticum aestivum L.) is a major crop to feed the world's population. Out of the total world production, about $53 \%$ is used in developed countries, and around $85 \%$ usage is reported in the developing countries (Denčić et al., 2011). In 2010, 647,497 hectares (ha) of wheat were planted in Nebraska and 602,981 ha were harvested with an average yield of $2891.75 \mathrm{~kg} / \mathrm{ha}$ for a total production of $1,743,985.4$ ton. But only small proportion of this production was produced organically. However, the demand of organic products continues to increase because organic wheat is an indispensable ingredient in many processed organic products. However, there has to date been little attention paid by public wheat breeders to evaluate and develop cultivars adapted specifically to organic production systems. Remedying this lack of information and lack of truly adapted lines is of paramount importance because the traits needed for organic production are not the same as those needed for conventional production (Baenziger et al., 2011). In general, winter wheat cultivars are being used by organic farmers under conventional high-input conditions, however, these cultivars may not reach their full genetic potential because organic soils are frequently limited in nutrients and fertilizers. Better nutrient uptake efficiency would be of great value for organic farms and conventional farms producing under low-input conditions (Hildermann et al., 2008). For this reason, winter wheat cultivars are being developed that will improve profitability and competitiveness of organic producers (Baenziger et al., 2011). However, it

\section{${ }^{*}$ Corresponding author:}

Osval Antonio Montesinos-López, Faculty of Telematic, University of Colima, E-mail: oamontes2@hotmail.com

Emeterio Franco-Pérez, Faculty of Marketing, University of Colima. Av. Universidad 333, Col. Las Víboras, C.P. 28040, Colima, México.

E-mail: francoperez@ucol.mx 
is important to evaluate lines under organic production conditions in different environments. Multienvironment trials are important in plant breeding for evaluating genotypes for their overall stability and adaptability in the presence of genotype by environment (GE) interaction. An understanding of GE interaction is important at all stages of plant breeding, including ideotype design, parent selection, selection based on traits, including grain yield (Yan et al., 1998). The GE interaction causes should be identified in order to establish breeding objectives, identify ideal testing locations and conditions, and come up with suggestions for areas of optimal cultivar adaptation. Many studies had been conducted to study the GE interaction in winter wheat. For example, Mengistu et al. (2010) reported hard winter wheat cultivar blends for the grain yield between blends and their component cultivars over several locations in Nebraska to compare blend grain yield stability and they found that when compared with the average of component cultivars in the blend, cultivar blends were more stable over different environments with little or no reduction in grain yield. Taghouti et al. (2010) studied GE interaction for quality traits in durum wheat (Triticum durum L.) cultivars adapted to different environments. They concluded that the genetic variation for sedimentation volume, yellow pigment index and grain volume weight was larger than the environmental variation, indicating the greater influence of genotypes of these traits. However, for vitreousness and protein content, the environmental effect was greater than the genetic effect. These studies show that wheat yield and other agronomic and quality traits vary considerably as a result of genotype, environment and their interaction (Allard et al.,1964; Basford et al., 1998; Trethowan et al., 2007;Denčić et al., 2011). For these reasons, to develop excellent winter wheat cultivars for organic production, it is extremely important to select and test lines in organic systems in different ecological regions. For this reason, the main contribution of this paper will be that it is the first one that evaluate GE interaction of winter wheat cultivar under organic production. To develop organic wheat cultivars suited to increase competitiveness and profits of organic producers in Nebraska and the Northern Great Plains. The objective of this study was to evaluate the performance of 36 wheat winter lines for organic systems in three locations in Nebraska (Clay, Dixon and Saunders counties) to: (1) To compare the performance of the released cultivars with experimental lines to help in the process of selection, (2) to study the magnitude and behavior of genotype-by-environment interaction for six agronomic traits (grain yield, anthesis date, plant height, protein content, grain volume weight and vegetation index) and (3) to identify the more stable genotypes for these traits.

\section{MATERIALS AND METHODS}

\section{Cultivar selection and growth conditions}

Thirty-six hard winter wheat lines were used in this study of which 20 lines were released. Clarkscream and Buckskin were released in the early 1970's. Lyman and McGill were released in 2009 and 2010 respectively and the other 16 were released before 2009. Sixteen lines are under consideration for release. The lines were grown in three Nebraska locations (Dixon, Clay and Saunders counties) that are in the western cornbelt ecoregion. The general attributes of each location are given in Table 1. Locations hereafter referred to by their respective counties.

\section{Traits measured}

Yield is measured in kilograms per ha $\left(\mathrm{kg} \mathrm{ha}^{-1}\right)$. Grain volume weight $(G V W)$ is the weight of a sample of grain in a small cup, converted to kilograms per hectoliter $\left(\mathrm{kg} / \mathrm{hl} \mathrm{kg} \mathrm{hl}{ }^{-1}\right)$. Anthesis date (Adate) is the date in May at which half of the tillers in a plot reach anthesis (indicated by visible emergence of anthers). The Normalized Difference Vegetation Index (NDVI) is the relative reflectance of plant material and soil at two wavelengths: Visible $($ red, $660 \mathrm{~nm})$ and infra-red (NIR, $770 \mathrm{~nm})$. NVDI = $(\pi \mathrm{NIR}-\pi \mathrm{VIS}) /(\pi \mathrm{NIR}+\pi \mathrm{VIS})$. NDVI was measured with a hand-held Greenseeker ${ }^{\circledR}$ at 0.6096 meters (m) above the canopy, and is the average of 40 to 60 measurements per plot. Measurements were taken at Feekes 7 or 8 stage. Height is the visual average distance from soil to top of the head excluding awns for mature plants for each plot and was measured in cms. Protein content was measured by near infra-red reflectance (NIR) as a grams of protein per $\mathrm{kg}\left(\mathrm{g} \mathrm{kg}^{-1}\right)$ of flour using a FOSS Tecator NIR.

\section{Design and analysis}

At each location in 2011, the 36 lines were grown in a randomized complete block design (RCBD) and we measured grain yield, anthesis date, plant height, protein content, GVW, and NDVI. In Clay all traits had 6 replication with exception of Adate which was only measured in the first two repetitions. In Dixon all the traits were measured on 4 replications, while in Saunders all the traits were measured on 5 replications with the exception of anthesis date which was measured using 4 replicates. The combined linear model over all locations for one trait, $Y_{l}$, is:

$Y_{i j k l}=\mu_{l}+E_{j l}+R(E)_{j k l}+G_{i l}+G E_{i l j}+\varepsilon_{i j k l}$

where $\mu_{l}$ is the mean effect on trait $l, E_{j l}$ is the effect of location $j$ on trait $l, R(E)_{j k l}$ is the effect of block $k$ within location $j$ on trait $l, G_{i l}$ is the effect of genotype (or pedigree) $i$ on trait $l, G E_{i l j}$ is the effect of the 
Table 1: Attributes of each location

\begin{tabular}{lccc}
\hline Attributes & & Location & \\
\cline { 2 - 4 } & Dixon & Clay county & Saunders \\
\hline Longitude & 96.57 .31 .7 & 98.08 .40 .4 & 92.29 .40 .6 \\
Latitude & 42.23 .03 .0 & 40.34 .29 .5 & 41.09 .14 .3 \\
Previous crop & oats/clover & Soybeans & Soybeans \\
Tillage after previous crop & Disc & Rototill & None \\
Soil test & NA & NA & NA \\
Soil type & Nora Silty Clay Loam & Hastings Silt Loam & Tomek Silt Loam \\
Planting date & $9 / 30 / 2011$ & $10 / 8 / 2011$ & $10 / 7 / 2011$ \\
Row spacing & 7.5 inches & 7.5 inches & 7.5 inches \\
Planting depth & 1.0 to 1.5 inches & 1.5 inches & 0.5 to 1.5 inches \\
\hline
\end{tabular}

interaction between genotype $i$ and environment $j$ on trait $l$, and $\varepsilon_{i j k l}$ is the random experimental error effect associated with genotype $i$ and block $k$ within location $j$ on trait $l$. All variance components need eg $\mathrm{R}(E)_{j k l} \sim N\left(0, \sigma_{\mathrm{R}(E)}^{2}\right), G_{i l} \sim N\left(0, \sigma_{G}^{2}\right), G E_{i l j} \sim N\left(0, \sigma_{G E}^{2}\right)$ and $\varepsilon_{i j k l} \sim N\left(0, \sigma^{2}\right)$, are assumed random, while locations, were considered fixed, because only three environments were studied.

An ANOVA was performed for each location and for each response variable using a RCBD. A combined ANOVA over the three locations (Clay, Dixon and Saunders) was performed for each trait after checking the homogeneity of error variances. We estimated Heritability $\left(b^{2}\right)$ according to (Cooper et al., 1994) from the analysis of variance. The broad sense heritability over all environments was calculated as $h^{2}=\frac{\sigma_{G}^{2}}{\sigma_{G}^{2}+\sigma_{G E}^{2} / r+\sigma_{E}^{2} / r L}, \sigma_{G}^{2}$ denotes the genotypic variance, $\sigma_{G E}^{2}$ denotes the genotype-environment interaction variance, $\sigma_{E}^{2}$ is the residual error variance, $L$ is the number of locations and $r$ is the number of replications. Genotypic and phenotypic correlations between traits were estimated using REML following (Holland, 2006). The combined linear models over all traits and locations is given by:

$$
\begin{aligned}
Y_{i j k l}= & \mu+E(\operatorname{Tr} a i t)_{j l}+\mathrm{R}(\mathrm{E})(\operatorname{Tr} a i t)_{j k l} \\
& +G(\operatorname{Tr} a i t)_{i l}+G E(\operatorname{Tr} a i t)_{i l j} \\
& +\varepsilon_{i j k l}(\operatorname{Tr} a i t)
\end{aligned}
$$

Where $\mu$ the overall mean and is fixed term, $E(\operatorname{Tr} \text { a } i t)_{j l}$ is considered a fixed term because we have only three environments, $R(E)(\text { Trait })_{j k l} \sim N\left(0, \sigma_{R(E)(\text { Trait })}^{2}\right)$, $G(\text { Trait })_{i l} \sim N\left(0, \sigma_{G(\text { Trait })}^{2}\right), G E(\text { Trait })_{i l j} \sim N\left(0, \sigma_{G E(T r a i t)}^{2}\right)$, and $\varepsilon_{i j k l}(\operatorname{Tr} a i t) \sim N\left(0, \sigma^{2}\right)$. Using this model
(Eq. 2) we can estimate the genetic covariance, the GE covariance and the error covariance matrices. For estimating the phenotypic correlation matrix among locations in model (2) we exchange Trait by E and vice versa. All analyses were performed using SAS software (SAS, 2003).

\section{Site regression model (SREG)}

To characterize the genotype and GE covariance matrices, the SREG (Crossa et al., 2002; Crossa and Cornelius, 1997) model was used. The SREG model is equal to

$\bar{y}_{i j}=\mu_{j}+\sum_{k=1}^{t} \lambda_{k} \alpha_{i k} \gamma_{j k}+\bar{\varepsilon}_{i j}$

Where $\bar{y}_{i j}$ is the mean of a trait of the $i t h$ cultivar in the $j$ th environment for $g$ genotypes and $L$ locations $(i=1,2, \ldots, g$ and $j=1,2, \ldots, L) ; \propto_{j}$ is the site mean; $\lambda_{k}\left(\lambda_{1} \geq \lambda_{2} \geq, \ldots, \lambda_{t}\right)$ are singular values scaling constants) that allow the imposition of orthonormality constraints on the singular vectors for genotypes, $\alpha_{k}=\left(\alpha_{1 k}, \ldots, \alpha_{g k}\right)^{\prime}$ and locations, $\gamma_{k}=\left(\gamma_{1 k}, \ldots, \gamma_{e k}\right)^{\prime}$, such that $\sum_{i} \alpha_{i k}^{2} \sum_{j} \gamma_{j k}^{2}=1$ and $\sum_{i} \alpha_{i k} \alpha_{i k^{\prime}} \sum_{j} \gamma_{j k} \gamma_{j k^{\prime}}=0$

for $k \neq k^{\prime} \cdot \alpha_{i k}$ and $\gamma_{j k}$ for $k=1,2, \ldots$, are called "primary," "secondary," "tertiary," effects of the $i$ th cultivar and the $j t h$ location, respectively; $\bar{\varepsilon}_{i j}$ is the residual error assumed to be normally and independent distributed with mean of zero and variance $\sigma^{2} / r$ (where $\sigma^{2}$ is the pooled error variance and $r$ is the number of replicates). The number of bilinear terms is $t \leq \mathrm{m}$ in $(g, L)$. Estimates of the multiplicative parameters in the kth bilinear term are obtained as the kth component of the deviations from the additive part of the model. In the SREG model, only the main effects of cultivars plus the $\mathrm{G} \times \mathrm{E}$ interaction are absorbed into the bilinear terms (Crossa and Cornelius, 1997). 
The SREG biplots plot the primary and secondary effects of genotypes and locations. Useful conclusions can be drawn from the biplot about relationships among environments, genotypes and GE interaction. For example, environments located in the same direction of the biplot equally discriminate genotypes, whereas locations in the opposite direction ranked the genotypes differently. (Crossa et al., 2002) pointed out that if the primary effects of locations were all of the same sign, the first component in biplots of SREG would be related to non-crossover genotype plus GE interaction variability, whereas the second component accounted for crossover genotype plus GE interaction variability, such that the ideal test environment or the genotype should have a large first primary effect and a nearzero secondary effect (Yan et al., 2001; Yan et al., 2007).

\section{RESULTS}

Means on individual locations indicated as average grain yield for all lines ranged from $3042.27 \mathrm{~kg} \mathrm{ha}^{-1}$ at Dixon (Table 2) to $3515.88 \mathrm{~kg} \mathrm{ha}^{-1}$ at Saunders (Table 3). Average Adate for all lines ranged from 26.3 days at Saunders (Table 3) to 41.3 days at Dixon (Table 2). For plant height, the average for all lines ranged from $79 \mathrm{cms}$ at Dixon (Table 2) to $96.28 \mathrm{cms}$ at Saunders (Table 3). For protein content the average ranged from 124.21 at Dixon (Table 2) to 126.04 grams per $\mathrm{kg}$ of flour at Saunders (Table 3). For GVW the average for all lines is between $69.94 \mathrm{~kg} \mathrm{hl}^{-1}$ at Saunders (Table 3) to $72.94 \mathrm{~kg} \mathrm{hl} \mathrm{l}^{-1}$ at Clay (Table 3). Finally, average NDVI for all lines ranged from 0.4044 at Dixon (Table 2) to 0.7175 at Saunders (Table 3). The lowest heritability on individual locations was for Adate (for all the genotypes) ranged from 0.2 at Cay (Table 8) to 0.79 at Saunders (Table 3). While the largest heritability was for protein content ranged from 0.90 at Dixon (Table 2) to 0.97 at Saunders (Table 3).

The combined analysis of variance for the six traits (grain yield, Adate, height, protein content, GVW and NDVI) is presented in Table 7. Genotypic effect was highly significant $(\mathrm{P}<0.01)$ across the three locations for all the six traits except for Adate that was not significant $(\mathrm{P}>0.1)$. While the effects of location were highly significant $(\mathrm{P}<0.01)$ for the six traits (Table7). Also the GxE interaction was highly significant $(\mathrm{P}<0.01)$ for five traits except for plant height that was marginally significant $(\mathrm{P}<0.1)$ (Table 7). This means that there are differential responses of the lines relative to each other across the three locations of Nebraska, which implies that the selection of lines should be focused on either genotypes with excellent adaptation to specific locations or stable genotypes that perform well in the three across environments (Mengistu et al., 2010).
For each trait the variation among genotypes was partitioned to compare released cultivars to experimental lines. McGill compared with the average of the experimental lines was highly significant $(\mathrm{P}<0.01)$ for plant height, GVW and protein content, but was not significant for grain yield, NDVI, and Adate (Table 7). Lyman was highly significant $(\mathrm{P}<0.01)$ for four traits (NDVI, plant height, GVW and protein content) but not significant for grain yield and Adate when compared with the average of the experimental lines (Table 7). The average of Lyman plus McGill, compared with the average of experimental lines were highly significant $(\mathrm{P}<0.01)$ for four traits (NDVI, plant height, GVW and protein) but not significant for yield and Adate. While the average of Buckskin plus Clarkscream vs the average of experimental lines (Table 7) were highly significant $(\mathrm{P}<0.01)$ for four traits grain yield, plant height, GVW and protein. However, the average grain yield of the experimental lines was higher by $135.45 \mathrm{~kg} \mathrm{~h} \mathrm{a}^{-1}$ over the average yield of the released cultivars, and was higher by $683.20 \mathrm{~kg} \mathrm{~h} \mathrm{a}^{-1}$ over the average of the older cultivars (Buckskin plus Clarkscream). The average of the experimental cultivars for NDVI was 0.06428 lower than the average of Lyman, was 0.03472 lower that the average of Lyman plus McGill, was 0.01936 lower that the average of Buckskin plus Clarkscream and was 0.01575 lower than the released cultivars. For plant height, the average of the experimental lines was lower by 3.54, 5.48, 5.51, 20.84, 2.66 cms compared with the McGill, Lyman, Lyman plus McGill, Buckskin plus Clarkscream and released lines, respectively. For GVW the average of the experimental lines was lower by $0.84,1.68,1.26,0.90$, $0.53 \mathrm{~kg} / \mathrm{hl}$ compared with the McGill, Lyman, Lyman plus McGill, Buckskin plus Clarkscream and released lines, respectively. Finally, in protein content the average of the experimental lines was higher by $2.85 \mathrm{~g} / \mathrm{kg}$ over the average of McGill. However, the average of the experimental lines was lower by $12.77,4.96,11.72,3.70 \mathrm{~g} \mathrm{~kg}^{-1}$ compared to Lyman, Lyman plus McGill, Buckskin plus Clarkscream and released lines, respectively. When comparing Karl 92 vs experimental lines only there was a highly significant $(\mathrm{P}<0.01)$ difference for grain yield plant height and protein content. Expedition vs experimental lines only differ significantly $(\mathrm{P}<0.01)$ for grain volume weight. While Camelot vs experimental lines only differed significantly $(\mathrm{P}<0.01)$ for protein content. The average of McGill plus Camelot only differed from the average of experimental lines for grain volume weight $(\mathrm{P}<0.01)$ and for plant height $(\mathrm{P}<0.05)$. When comparing the average of Lyman plus Expedition vs the experimental lines only there were no significant differences for grain yield and for Adate $(\mathrm{P}>0.05)$.

\section{Site regression model (SREG)}

For each response variable (grain yield, NDVI, Adate, plant height, GVW and protein content) we created SREG biplot 
Montesinos-López, et al.

Table 2: Mean performance (Blups and blues) and heritability for each trait in location Dixon for the 36 lines studied

\begin{tabular}{|c|c|c|c|c|c|c|c|c|}
\hline \multicolumn{3}{|c|}{ Blup } & \multicolumn{6}{|c|}{ Blue } \\
\hline Entry & Pedigree & Yield & Yield & Adate & Height & Protein & GVW & NDVI \\
\hline 1 & Hatcher & 2567.67 & 2397.46 & 42.50 & 71.12 & 123.50 & 71.94 & 0.3370 \\
\hline 2 & Camelot & 3155.46 & 3196.06 & 44.00 & 78.11 & 125.50 & 74.47 & 0.3688 \\
\hline 3 & $\mathrm{Ne} 03490$ & 3045.33 & 3046.43 & 42.75 & 70.49 & 118.50 & 72.06 & 0.3868 \\
\hline 4 & Wahoo & 3459.88 & 3609.64 & 40.25 & 85.09 & 122.25 & 72.03 & 0.4713 \\
\hline 5 & Goodstreak & 3254.46 & 3330.56 & 43.75 & 95.25 & 128.75 & 75.22 & 0.4183 \\
\hline 6 & Pronghorn & 3070.08 & 3080.05 & 39.75 & 86.36 & 126.50 & 74.38 & 0.3965 \\
\hline 7 & Buckskin & 3016.87 & 3007.76 & 41.50 & 96.52 & 125.50 & 74.19 & 0.4828 \\
\hline 8 & Clarkscream & 2339.98 & 2088.11 & 39.50 & 100.33 & 140.25 & 73.63 & 0.3328 \\
\hline 9 & Danby & 2744.63 & 2637.88 & 44.25 & 74.93 & 116.25 & 73.06 & 0.3815 \\
\hline 10 & Alice & 2846.10 & 2775.74 & 40.75 & 68.58 & 125.00 & 72.78 & 0.4055 \\
\hline 11 & Karl92 & 2599.84 & 2441.18 & 40.75 & 66.68 & 130.25 & 72.94 & 0.3925 \\
\hline 12 & Darrell & 3248.27 & 3322.15 & 39.50 & 83.19 & 123.25 & 73.75 & 0.4223 \\
\hline 13 & NE99495 & 3166.60 & 3211.19 & 42.25 & 77.47 & 125.25 & 72.53 & 0.4085 \\
\hline 14 & Wesley & 2907.97 & 2859.81 & 42.75 & 72.39 & 129.25 & 71.66 & 0.3780 \\
\hline 15 & Alliance & 2846.10 & 2775.74 & 43.25 & 79.38 & 115.25 & 73.38 & 0.4528 \\
\hline 16 & Millennium & 3127.00 & 3157.39 & 41.75 & 82.55 & 126.25 & 73.69 & 0.3693 \\
\hline 17 & Overland & 3419.04 & 3554.16 & 41.25 & 78.74 & 121.75 & 74.28 & 0.4505 \\
\hline 18 & Expedition & 3140.61 & 3175.88 & 42.00 & 78.11 & 120.50 & 73.66 & 0.4250 \\
\hline 19 & McGill & 2982.22 & 2960.68 & 38.75 & 80.65 & 120.25 & 73.09 & 0.4000 \\
\hline 20 & NW03666 & 3290.34 & 3379.31 & 44.75 & 77.47 & 123.25 & 71.25 & 0.4118 \\
\hline 21 & NW07505 & 3045.33 & 3046.43 & 43.50 & 79.38 & 120.00 & 72.00 & 0.4170 \\
\hline 22 & NW03681 & 2990.88 & 2972.45 & 43.00 & 76.20 & 129.75 & 74.09 & 0.4430 \\
\hline 23 & NE04424 & 2886.93 & 2831.23 & 42.00 & 74.30 & 124.00 & 73.09 & 0.3630 \\
\hline 24 & NE05496 & 3165.36 & 3209.51 & 41.50 & 77.47 & 123.25 & 72.69 & 0.4190 \\
\hline 25 & NE05548 & 3129.48 & 3160.75 & 38.50 & 86.36 & 128.75 & 72.75 & 0.4468 \\
\hline 26 & NE08457 & 3056.47 & 3061.56 & 40.25 & 71.76 & 128.00 & 73.47 & 0.3915 \\
\hline 27 & NIO8708 & 2993.36 & 2975.81 & 41.25 & 71.76 & 121.00 & 70.31 & 0.4023 \\
\hline 28 & NE02558 & 2895.60 & 2842.99 & 39.00 & 75.57 & 123.00 & 72.22 & 0.3493 \\
\hline 29 & NE06545 & 3223.52 & 3288.53 & 39.25 & 75.57 & 118.50 & 72.06 & 0.3608 \\
\hline 30 & NE07444 & 3036.67 & 3034.66 & 40.25 & 78.11 & 124.75 & 73.38 & 0.3888 \\
\hline 31 & NE05425 & 2974.79 & 2950.59 & 39.50 & 72.39 & 126.00 & 72.78 & 0.4075 \\
\hline 32 & NE05430 & 3334.89 & 3439.84 & 41.50 & 87.00 & 122.00 & 73.41 & 0.4153 \\
\hline 33 & SD07165 & 3223.52 & 3288.53 & 40.00 & 76.20 & 118.75 & 72.59 & 0.4788 \\
\hline 34 & Hallam & 3369.54 & 3486.91 & 42.00 & 81.92 & 120.25 & 69.94 & 0.4060 \\
\hline 35 & Lyman & 3223.52 & 3288.53 & 42.50 & 83.19 & 136.50 & 75.38 & 0.4655 \\
\hline \multirow[t]{8}{*}{36} & NX05M41806 & 2743.39 & 2636.20 & 38.25 & 73.66 & 119.75 & 69.06 & 0.3135 \\
\hline & Var_Entry & & 80437.03 & 2.15 & 54.71 & 23.89 & 1.70 & 0.0011 \\
\hline & Var_Resid & & 115389.50 & 3.52 & 9.50 & 10.23 & 0.50 & 0.0023 \\
\hline & Gmean & & 3042.27 & 41.34 & 79.00 & 124.21 & 72.87 & 0.4044 \\
\hline & LSD & & 476.27 & 2.63 & 4.32 & 4.48 & 0.99 & 0.0676 \\
\hline & CV & & 7.90 & 3.21 & 2.76 & 1.82 & 0.69 & 8.4281 \\
\hline & Heritability & & 0.74 & 0.71 & 0.96 & 0.90 & 0.93 & 0.6519 \\
\hline & Nreps & & 4 & 4 & 4 & 4 & 4 & 4 \\
\hline
\end{tabular}

of the 36 genotypes, which are depicted in Fig. 1. The three locations (environments) are located to the right side of the biplot for all the traits measured with the exception of Adate. For grain yield and NDVI the first SREG component explained $68.22 \%$ and $55.93 \%$ respectively of the genotype plus GE interaction, whereas the second component accounted for $21.22 \%$ and $32.72 \%$ of the variability respectively (Fig. 1A and 1B). This means that the grain yield and NDVI are substantially variable from location to location.
With regard to the grain yield in Fig. 1A genotypes NW03666, SD07165, NE07444 and Overland have a positive response in terms of genotype and GE interaction for the three locations because they are in the same direction. This mean that these 4 genotypes produce the best yield which is in agreement with the combined analysis given in Table 4, where we can see that the yield for these four genotypes are 3444.39, 3521.25, 3299.00 and 3546.46 $\mathrm{kg} \mathrm{ha}{ }^{-1}$ respectively. On the other hand, genotypes 
Montesinos-López, et al.

Table 3: Mean performance (blups and blues) and heritability for each trait in location Sunders for the 36 lines studied

\begin{tabular}{|c|c|c|c|c|c|c|c|c|}
\hline \multicolumn{3}{|c|}{ Blup } & \multicolumn{6}{|c|}{ Blue } \\
\hline Entry & Pedigree & Yield & Yield & Adate & Height & Protein & GVW & NDVI \\
\hline 1 & Hatcher & 3397.71 & 3382.68 & 26.25 & 87.88 & 126.20 & 68.35 & 0.7264 \\
\hline 2 & Camelot & 3692.02 & 3713.55 & 26.25 & 95.50 & 126.80 & 68.50 & 0.7658 \\
\hline 3 & $\mathrm{Ne} 03490$ & 3823.99 & 3871.84 & 26.25 & 88.39 & 116.60 & 70.08 & 0.6638 \\
\hline 4 & Wahoo & 3473.08 & 3467.41 & 27.25 & 99.06 & 125.60 & 69.63 & 0.7338 \\
\hline 5 & Goodstreak & 3596.98 & 3609.56 & 26.75 & 110.74 & 141.20 & 72.98 & 0.7818 \\
\hline 6 & Pronghorn & 2974.21 & 2906.55 & 26.00 & 102.62 & 131.40 & 71.08 & 0.7354 \\
\hline 7 & Buckskin & 2986.17 & 2920.00 & 26.50 & 115.82 & 128.60 & 68.58 & 0.7572 \\
\hline 8 & Clarkscream & 2622.48 & 2511.12 & 26.75 & 123.44 & 145.60 & 70.58 & 0.7040 \\
\hline 9 & Danby & 3638.18 & 3653.02 & 26.25 & 89.41 & 120.00 & 72.40 & 0.6672 \\
\hline 10 & Alice & 3177.59 & 3135.20 & 25.50 & 83.82 & 126.80 & 69.88 & 0.7458 \\
\hline 11 & Karl92 & 3357.04 & 3336.95 & 25.25 & 83.82 & 138.80 & 69.18 & 0.7424 \\
\hline 12 & Darrell & 3232.62 & 3197.07 & 27.25 & 98.04 & 127.80 & 71.15 & 0.6572 \\
\hline 13 & NE99495 & 3564.01 & 3569.63 & 26.00 & 93.98 & 129.00 & 69.55 & 0.7822 \\
\hline 14 & WESLEY & 3723.12 & 3748.52 & 26.75 & 82.80 & 128.40 & 70.48 & 0.7152 \\
\hline 15 & Alliance & 3477.87 & 3472.79 & 25.75 & 98.55 & 118.40 & 69.83 & 0.6728 \\
\hline 16 & Millennium & 3477.87 & 3472.79 & 27.75 & 98.04 & 125.40 & 71.23 & 0.6850 \\
\hline 17 & Overland & 3799.69 & 3834.60 & 27.00 & 97.03 & 122.40 & 70.18 & 0.6466 \\
\hline 18 & Expedition & 3778.15 & 3810.39 & 26.25 & 91.95 & 124.00 & 70.63 & 0.6884 \\
\hline 19 & McGill & 3611.86 & 3623.43 & 26.25 & 96.52 & 121.20 & 70.58 & 0.6820 \\
\hline 20 & NW03666 & 3616.65 & 3628.81 & 26.25 & 97.03 & 121.00 & 68.78 & 0.6910 \\
\hline 21 & NW07505 & 3396.52 & 3381.33 & 26.00 & 97.03 & 123.60 & 69.73 & 0.7688 \\
\hline 22 & NW03681 & 3379.77 & 3362.50 & 27.25 & 93.47 & 135.20 & 72.00 & 0.7072 \\
\hline 23 & NE04424 & 3547.26 & 3550.80 & 26.50 & 93.98 & 123.60 & 71.70 & 0.6946 \\
\hline 24 & NE05496 & 3626.22 & 3639.57 & 26.25 & 92.46 & 124.40 & 70.25 & 0.6908 \\
\hline 25 & NE05548 & 3379.77 & 3362.50 & 27.75 & 108.20 & 132.80 & 70.70 & 0.6906 \\
\hline 26 & NE08457 & 3787.72 & 3821.15 & 26.25 & 90.42 & 132.20 & 70.53 & 0.7234 \\
\hline 27 & NIO8708 & 4031.78 & 4095.53 & 25.75 & 93.98 & 122.00 & 68.98 & 0.7764 \\
\hline 28 & NE02558 & 3555.63 & 3560.22 & 25.00 & 96.01 & 118.00 & 70.13 & 0.6708 \\
\hline 29 & NE06545 & 3934.87 & 3986.58 & 25.50 & 88.90 & 116.20 & 69.73 & 0.7504 \\
\hline 30 & NE07444 & 3476.67 & 3471.45 & 26.00 & 98.04 & 122.20 & 69.78 & 0.7250 \\
\hline 31 & NE05425 & 3638.18 & 3653.02 & 25.50 & 90.93 & 124.40 & 68.15 & 0.7280 \\
\hline 32 & NE05430 & 3430.01 & 3418.99 & 26.50 & 107.19 & 122.20 & 69.30 & 0.7124 \\
\hline 33 & SD07165 & 3796.10 & 3830.56 & 25.75 & 95.00 & 122.80 & 70.45 & 0.7234 \\
\hline 34 & Hallam & 3580.75 & 3588.46 & 26.25 & 97.03 & 124.00 & 66.85 & 0.6938 \\
\hline 35 & Lyman & 3595.11 & 3604.60 & 27.00 & 101.60 & 135.00 & 71.03 & 0.7990 \\
\hline \multirow[t]{7}{*}{36} & NX05M41806 & 3394.12 & 3378.64 & 26.25 & 87.38 & 113.80 & 65.13 & 0.7296 \\
\hline & Var_Entry & & 86268.09 & 0.33 & 70.24 & 47.39 & 2.04 & 0.0009 \\
\hline & Var_Resid & & 53595.45 & 0.34 & 21.86 & 8.14 & 0.84 & 0.0034 \\
\hline & Gmean & & 3515.88 & 26.33 & 96.28 & 126.04 & 69.94 & 0.7175 \\
\hline & LSD & & 291.50 & 0.82 & 5.85 & 3.58 & 1.15 & 0.0725 \\
\hline & CV & & 4.19 & 1.58 & 3.07 & 1.44 & 0.83 & 5.1091 \\
\hline & Heritability & & 0.89 & 0.79 & 0.94 & 0.97 & 0.92 & 0.5604 \\
\hline | & Nreps & & 5 & 4 & 5 & 5 & 5 & 5 \\
\hline
\end{tabular}

Hatcher, NX05M41806 and Clarkscream are located on the opposite side of the biplot, this mean that they have a negative response in all sites. The grain yield of these genotypes are 2956.63, 2899.07 and $2563.12 \mathrm{~kg} \mathrm{ha}^{-1}$ respectively (Table 4 for yield). For NDVI genotypes Lyman and Buckskin have a positive response in terms of genotype and GE for the three sites because they are in the same direction and their corresponding means are 0.6535 and 0.6558 respectively. While genotype NX05M41806 have a negative response in all sites (in opposite side of the biplot) with a mean of 0.5259 (See table 4 for NDVI).

While, for GVW, Adate, protein content and height the contribution of the first and second component was $81.47 \%$ and $12.44 \%$ (Fig. 1E); $74.67 \%$ and 16.27 (Fig. 1C); 93.97 and $4.78 \%$ (Fig. 1F) and, 95\% and 3.19\% (Fig. 1D), respectively. Recalling that a stable location demonstrates a large first primary effect (non-crossover GE variability) and near zero second effect (Crossover GE variability) in 
Table 4: Mean performance (blups and blues) and heritability for each trait in the 3 locations (combined analysis) for the 36 lines studied

\begin{tabular}{|c|c|c|c|c|c|c|c|c|}
\hline \multicolumn{3}{|c|}{ Blup } & \multicolumn{6}{|c|}{ Blue } \\
\hline Entry & Pedigree & Yield & Yield & Adate & Height & Protein & GVW & NDVI \\
\hline 1 & Hatcher & 2870.06 & 2956.63 & 33.21 & 80.40 & 125.05 & 70.85 & 0.5751 \\
\hline 2 & Camelot & 3366.80 & 3339.72 & 33.34 & 86.71 & 126.45 & 72.01 & 0.6050 \\
\hline 3 & NE03490 & 3432.33 & 3389.37 & 33.03 & 80.88 & 117.85 & 71.73 & 0.5667 \\
\hline 4 & Wahoo & 3369.40 & 3341.70 & 32.34 & 90.37 & 123.80 & 71.27 & 0.6277 \\
\hline 5 & Goodstreak & 3377.22 & 3347.12 & 33.57 & 100.07 & 133.41 & 74.20 & 0.6357 \\
\hline 6 & Pronghorn & 3034.78 & 3083.65 & 31.43 & 94.02 & 129.28 & 72.71 & 0.6146 \\
\hline 7 & Buckskin & 2920.24 & 2995.30 & 32.53 & 103.75 & 127.30 & 72.27 & 0.6558 \\
\hline 8 & Clarkscream & 2359.84 & 2563.12 & 31.75 & 109.32 & 142.47 & 72.77 & 0.5614 \\
\hline 9 & Danby & 3157.71 & 3178.48 & 33.16 & 82.16 & 118.86 & 73.83 & 0.5646 \\
\hline 10 & Alice & 2999.31 & 3056.30 & 32.02 & 74.93 & 126.49 & 71.52 & 0.6239 \\
\hline 11 & Karl92 & 2954.99 & 3022.13 & 31.93 & 73.58 & 134.90 & 71.27 & 0.6155 \\
\hline 12 & Darrell & 3060.80 & 3103.70 & 31.80 & 90.30 & 126.74 & 72.83 & 0.5940 \\
\hline 13 & NE99495 & 3353.86 & 3329.74 & 32.62 & 85.38 & 127.12 & 71.66 & 0.6332 \\
\hline 14 & Wesley & 3243.35 & 3244.52 & 32.80 & 76.96 & 128.84 & 71.65 & 0.5924 \\
\hline 15 & Alliance & 3249.76 & 3249.48 & 32.75 & 88.74 & 116.61 & 71.72 & 0.6058 \\
\hline 16 & Millennium & 3336.54 & 3316.39 & 32.66 & 90.12 & 126.33 & 72.86 & 0.5694 \\
\hline 17 & Overland & 3634.87 & 3546.46 & 32.75 & 87.24 & 121.96 & 72.63 & 0.5951 \\
\hline 18 & Expedition & 3441.16 & 3397.07 & 32.34 & 83.91 & 123.11 & 72.31 & 0.5993 \\
\hline 19 & McGill & 3347.62 & 3324.94 & 31.70 & 89.23 & 120.32 & 72.45 & 0.5944 \\
\hline 20 & NW03666 & 3503.70 & 3444.39 & 33.89 & 86.07 & 121.19 & 70.82 & 0.5848 \\
\hline 21 & NW07505 & 3276.68 & 3270.22 & 33.48 & 89.52 & 121.48 & 71.65 & 0.6251 \\
\hline 22 & NW03681 & 3087.53 & 3124.33 & 33.48 & 84.04 & 132.25 & 73.61 & 0.6028 \\
\hline 23 & NE04424 & 3182.92 & 3197.91 & 32.57 & 83.18 & 123.46 & 72.80 & 0.5555 \\
\hline 24 & NE05496 & 3364.86 & 3338.22 & 32.57 & 86.64 & 123.94 & 71.96 & 0.5846 \\
\hline 25 & NE05548 & 3304.58 & 3291.74 & 32.30 & 96.22 & 130.60 & 72.17 & 0.6171 \\
\hline 26 & NE08457 & 3441.19 & 3397.10 & 32.11 & 79.34 & 130.54 & 72.52 & 0.5837 \\
\hline 27 & NIO8708 & 3458.90 & 3410.76 & 32.43 & 82.30 & 121.98 & 70.45 & 0.6104 \\
\hline 28 & NE02558 & 3174.20 & 3191.19 & 31.20 & 86.81 & 120.86 & 71.57 & 0.5546 \\
\hline 29 & NE06545 & 3603.30 & 3520.85 & 31.34 & 82.97 & 117.26 & 71.21 & 0.5959 \\
\hline 30 & NE07444 & 3313.99 & 3299.00 & 32.16 & 88.70 & 123.52 & 72.00 & 0.5916 \\
\hline 31 & NE05425 & 3264.11 & 3260.53 & 31.57 & 83.72 & 126.34 & 71.16 & 0.6096 \\
\hline 32 & NE05430 & 3365.81 & 3338.94 & 32.80 & 94.60 & 121.71 & 72.04 & 0.5980 \\
\hline 33 & SD07165 & 3602.16 & 3521.25 & 31.98 & 85.36 & 120.09 & 72.10 & 0.6212 \\
\hline 34 & Hallam & 3402.61 & 3367.32 & 32.75 & 88.63 & 122.36 & 68.91 & 0.5830 \\
\hline 35 & Lyman & 3274.57 & 3268.58 & 33.21 & 91.16 & 135.93 & 73.30 & 0.6535 \\
\hline \multirow[t]{11}{*}{36} & NX05M41806 & 2795.46 & 2899.07 & 31.25 & 80.63 & 117.55 & 68.08 & 0.5259 \\
\hline & Var_Loc & & 53064.15 & 61.91 & 74.47 & 0.00 & 2.89 & 0.0283 \\
\hline & Var_Entry & & 50016.06 & 0.00 & 53.17 & 32.13 & 1.24 & 0.0005 \\
\hline & Var_LocxEntry & & 29570.87 & 0.94 & 1.51 & 1.82 & 0.37 & 0.0005 \\
\hline & Var_Resid & & 73338.10 & 1.76 & 21.08 & 10.74 & 0.69 & 0.0023 \\
\hline & Gmean & & 3247.98 & 32.47 & 87.17 & 125.22 & 71.91 & 0.5980 \\
\hline & LSD & & 344.31 & 1.95 & 3.92 & 3.26 & 1.16 & 0.0520 \\
\hline & CV & & 5.32 & 3.01 & 2.25 & 1.31 & 0.81 & 4.3616 \\
\hline & Heritability & & 0.78 & 0.00 & 0.97 & 0.96 & 0.89 & 0.5945 \\
\hline & Nreps & & 6 & 4 & 6 & 6 & 6 & 6 \\
\hline & Nlocs & & 3 & 3 & 3 & 3 & 3 & 3 \\
\hline
\end{tabular}

the biplot (Crossa et al., 2002). These results showed that the three locations present a small but relevant variability for GVW and Adate. However, for protein and height the three locations are good because they had large values for primary effects (first PC) and low values for secondary effects (second PC). This implies that the 36 genotypes are stable for protein content and plant height in these three locations studied.

For GVW the genotypes with the best performance (positive response in terms of genotype and GE for the three locations) were Lyman, NW03681, Danby and 
Goodstreak with means equal to 73.30, 73.61, 73.83 and $74.20 \mathrm{~kg} \mathrm{~h} \mathrm{l}^{-1}$ respectively (Fig. 1E and Table 4). While the genotypes Hallam and NX05M41806 are located on the opposite side of the biplot, this mean that they have a negative response in all sites with means of 68.91 and 68.08 $\mathrm{kg} \mathrm{hl} l^{-1}$ respectively. On the other hand, for Adate all the genotypes are located in the center of the biplot and the three locations are spread to all sides. This mean that the behavior of the 36 genotypes is very similar in each location, which can be corroborated with Table 4 (for Adate) where the range of the means is between 31.2 to 33.9 days.

While for plant height, genotypes Goodstreak, Buckskin, and Clarkscream have the superior performance in terms of genotype and GE for the three locations because they are in the same direction and their corresponding means are 100.07, 103.75 and $109.32 \mathrm{cms}$ respectively. Contrarily, genotypes Karl92, Alice and Wesley are located on the opposite side of the biplot, this mean that they have a negative response in all sides with means of $73.58,74.93$ and $76.96 \mathrm{cms}$ respectively. For protein content genotypes Goodstreak, Karl 92, Lyman, and Clarkscream have the best performance in terms of genotype and GE in the three locations because they are in the same directions with means $133.41,134.90,135.93$ and 142.47 grams per $\mathrm{kg}$ of flour respectively. While genotypes Alliance, NX05M41806, Danby and NE02558 have the worst performance (on the opposite side of the biplot) with means 116.61, 117.55, 118.86 and 120.86 grams per $\mathrm{kg}$ of flour respectively.

\section{Genetic and phenotypic correlations}

For traits there was a large range in the genetic correlation among all pairwise comparisons between five of the six traits measured (Table 5). The lowest genetic correlation was 0.009 between GVW and grain yield, while the largest was -0.542 between protein content and yield. This is in agreement to the results given by (Marinciu et al., 2009)

\begin{tabular}{|c|c|c|c|c|c|}
\hline Trait & Yield & NDVI & Height & GVW & Protein \\
\hline Yield & 1 & 0.3 & -0.04 & 0.06 & -0.3 \\
\hline NDVI & 0.1 & 1 & 0.1 & 0.05 & 0.1 \\
\hline Height & -0.2 & 0.3 & 1 & 0.2 & 0.2 \\
\hline GVW & 0.009 & 0.4 & 0.3 & 1 & 0.2 \\
\hline Protein & -0.5 & 0.4 & 0.3 & 0.4 & 1 \\
\hline
\end{tabular}

Table 6: Phenotypic correlation coefficients among the three locations (Stae the Counties) for five traits (State the Traits)

\begin{tabular}{lccc}
\hline Location & Clay & Dixon & Saunders \\
\hline Clay & 1 & 0.3 & 0.5 \\
Dixon & & 1 & 0.3 \\
Saunders & & & 1 \\
\hline
\end{tabular}

that found a negative relationship between protein content and yield. The second largest correlation was 0.470 between NDVI and GVW. The correlation between GVW and protein content was 0.446 , while between height and GVW was 0.378 ; and between height and protein content was 0.360. The genetic correlation between NDVI vs plant height, GVW and protein content was $0.324,0.367$ and 0.434 respectively. Finally, the genetic correlation between grain yield and height was negative $(-0.282)$ and with regard to NDVI was positive but very low 0.157 . On the other hand, the phenotypic correlations had only two negative correlations. Similar to the genetic correlation, grain yield vs plant height $(-0.045)$ and grain yield vs protein content $(-0.353)$ were negatively correlated using phenoptyic values. The phenotypic correlation between grain yield, and GVW and NDVI was 0.066 and 0.305 respectively. The phenotypic correlation between NDVI and plant height, GVW and protein were 0.199, 0.056 and 0.118 respectively. The phenotypic correlation between plant height and GVW and protein content was 0.238 and 0.228 , respectively. Finally the correlation between GVW and protein content was 0.269 .

For locations we can see in Table 6 that the largest phenotypic correlation was 0.5175 between Clay and Saunders, while the lowest correlation was 0.35258 between Clay and Dixon, while the correlation between Dixon and Saunders was 0.39249 .

\section{DISCUSSION}

The grain yield and NDVI responses were highly significant and highly responsive. Their performance varied across locations which is reflected in the lowest broad sense heritability estimates. The average difference in the grain yield was $473.61 \mathrm{~kg} \mathrm{ha}^{-1}$ and the location with the highest grain yield was Saunders while Dixon had the lowest grain yield. For NDVI the average difference among locations was 0.3131 where again Saunders reported the highest values and Dixon the lowest. Although, GVW and Adate had little variability compared with grain yield and NDVI across locations we have not elements to guarantee that these trait are stable across locations, because there are also a highly significant effect of environment and GE. In this case for GVW the average difference between locations was of $3 \mathrm{~kg} \mathrm{hl}^{-1}$ where Saunders had the lowest value. While for Adate, the average difference was of 15 days where Dixon had the highest value and Saunders the lowest Adate value. For protein content the average difference was of $1.83 \mathrm{~g} \mathrm{~kg}^{-1}$ between Dixon (lowest) and Saunders (highest). For plant height the average difference was of $17.28 \mathrm{cms}$ between Dixon (lowest) and Saunders (highest). The site regression biplots (Fig. 1) show that the 

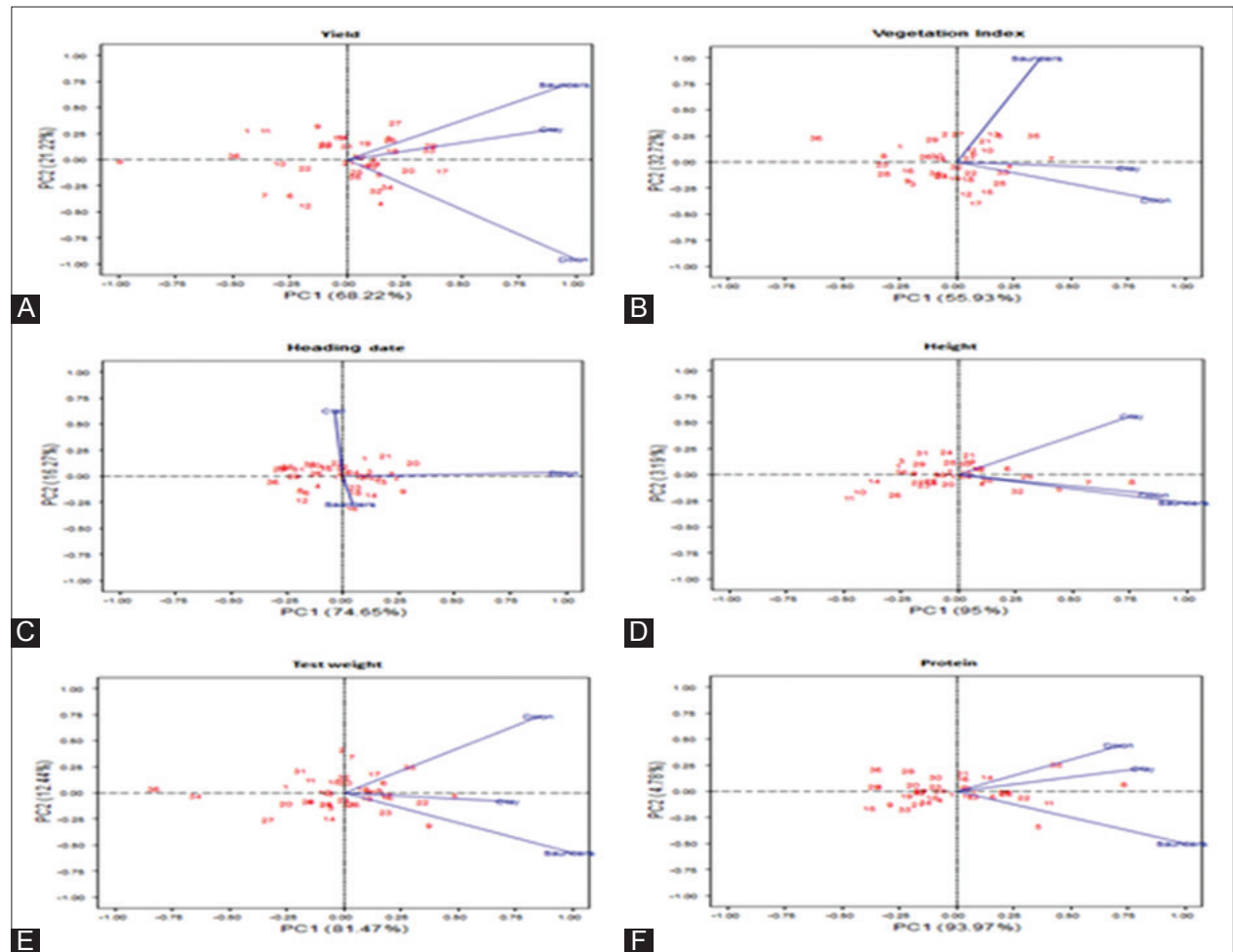

Fig 1. Side regression biplot of number of locations of 36 wheat lines in three environments in Nebraska, USA, for A) Yield B) the NDVI index, C) Adate, D) Height, E) GVW and F) protein.

Table 7: Analysis of variance for yield NDVI, Adate, height, GVW and protein in 36 lines of winter wheat across three environments in Nebraska 2011. GE means genotype by environment interaction

\begin{tabular}{|c|c|c|c|c|c|c|c|c|c|c|c|c|}
\hline \multirow[t]{2}{*}{ Source } & \multicolumn{2}{|c|}{ Yield } & \multicolumn{2}{|c|}{ Vgeindex } & \multicolumn{2}{|c|}{ Adate } & \multicolumn{2}{|c|}{ Height } & \multicolumn{2}{|c|}{ GVW } & \multicolumn{2}{|c|}{ protein } \\
\hline & DF & $\begin{array}{l}\text { Mean } \\
\text { square }\end{array}$ & DF & $\begin{array}{l}\text { Mean } \\
\text { square }\end{array}$ & DF & $\begin{array}{l}\text { Mean } \\
\text { square }\end{array}$ & DF & $\begin{array}{l}\text { Mean } \\
\text { square }\end{array}$ & DF & $\begin{array}{l}\text { Mean } \\
\text { square }\end{array}$ & DF & $\begin{array}{l}\text { Mean } \\
\text { square }\end{array}$ \\
\hline Environment (E) & 2 & $2178.4^{\star \star}$ & 2 & $4.4^{* *}$ & 2 & $8598.4^{\star *}$ & 2 & $1908.5^{\star \star}$ & 2 & $331.7^{\star *}$ & 2 & $1.3^{\star \star}$ \\
\hline Block (R) & 12 & $175.8^{* *}$ & 12 & $0.03^{* *}$ & 7 & 0.960 & 12 & $18.6^{\star \star}$ & 12 & $1.4^{\star *}$ & 12 & $3.8^{* *}$ \\
\hline Lines $(G)$ & 35 & $208.8^{* *}$ & 35 & $0.01^{* *}$ & 35 & 3.897 & 35 & $125.9^{* *}$ & 35 & $12.0^{* *}$ & 35 & $4.7^{\star *}$ \\
\hline McGill vs experimentals & 1 & 0.9 & 1 & 0.0002 & 1 & 2.986 & 1 & $26.3^{\star *}$ & 1 & $6.0^{\star *}$ & 1 & $1.0^{* *}$ \\
\hline Lyman vs experimentals & 1 & 4.2 & 1 & $0.05^{\star \star}$ & 1 & 4.63 & 1 & $67.5^{\star \star}$ & 1 & $24.2^{* *}$ & 1 & $21.3^{\star *}$ \\
\hline $\begin{array}{l}\text { Lyman-McGill vs } \\
\text { experimentals }\end{array}$ & 1 & 0.5 & 1 & $0.03^{* *}$ & 1 & 0.08 & 1 & $84.1^{\star *}$ & 1 & $25.9^{* *}$ & 1 & $6.3^{\star *}$ \\
\hline $\begin{array}{l}\text { Buckskin-Clarkscream } \\
\text { vs experimentals }\end{array}$ & 1 & $2656.7^{\star *}$ & 1 & $0.009^{*}$ & 1 & 1.460 & 1 & $1790.2^{* *}$ & 1 & $13.3^{* *}$ & 1 & $35.2^{* *}$ \\
\hline $\begin{array}{l}\text { Released vs } \\
\text { experimental }\end{array}$ & 1 & $506.9^{* *}$ & 1 & $0.02^{* \star}$ & 1 & 0.425 & 1 & $159.5^{\star *}$ & 1 & $23.7^{\star *}$ & 1 & $16.9^{* *}$ \\
\hline Karl92 vs experimentals & 1 & $434.3^{\star \star}$ & 1 & 0.008 & 1 & 1.545 & 1 & $299.7^{\star \star}$ & 1 & 0.899 & 1 & $18.3^{* *}$ \\
\hline $\begin{array}{l}\text { Camelot vs } \\
\text { experimentals }\end{array}$ & 1 & 6.8 & 1 & 0.003 & 1 & 5.7 & 1 & 2.3 & 1 & 1.5 & 1 & $1.4^{* *}$ \\
\hline $\begin{array}{l}\text { McGill-Camelot vs } \\
\text { experimentals }\end{array}$ & & 6.0 & 1 & 0.002 & 1 & 0.2 & 1 & $21.0^{*}$ & 1 & $6.3^{\star *}$ & 1 & 0.01 \\
\hline $\begin{array}{l}\text { Expedition vs } \\
\text { experimentals }\end{array}$ & 1 & 42.4 & 1 & 0.001 & 1 & 0.2 & 1 & 5.0 & 1 & $4.4^{* *}$ & 1 & 0.005 \\
\hline $\begin{array}{l}\text { Lyman-Expedition vs } \\
\text { experimentals }\end{array}$ & 1 & 9.3 & 1 & $0.03^{* *}$ & 1 & 1.2 & 1 & $16.8^{*}$ & 1 & $23.6^{* *}$ & 1 & $10.0^{* *}$ \\
\hline GE & 70 & $47.8^{* *}$ & 70 & $0.005^{\star *}$ & 70 & $4.6^{* *}$ & 70 & $4.3^{*}$ & 70 & $1.5^{\star *}$ & 70 & $0.1^{* *}$ \\
\hline Error & 416 & 16.1 & 418 & 0.002 & 245 & 1.8 & 420 & 3.2 & 408 & 0.4 & 412 & 0.1 \\
\hline CV(\%) & & 8.3 & & 7.8 & & 4.0 & & 5.2 & & 1.1 & & 2.6 \\
\hline Mean & & 48.3 & & 0.6 & & 33.0 & & 34.5 & & 57.5 & & 12.5 \\
\hline R-square & & 0.7 & & 0.9 & & 0.9 & & 0.8 & & 0.8 & & 0.8 \\
\hline
\end{tabular}


Montesinos-López, et al.

Table 8: Mean performance (blups and blues) and heritability for each trait in location Clay for the 36 lines studied

\begin{tabular}{|c|c|c|c|c|c|c|c|c|}
\hline \multicolumn{3}{|c|}{ Blup } & \multicolumn{6}{|c|}{ Blue } \\
\hline Entry & Pedigree & Yield & Yield & Adate & Height & Protein & GVW & NDVI \\
\hline 1 & Hatcher & 2856.34 & 2806.57 & 31.00 & 81.70 & 125.17 & 72.25 & 0.6563 \\
\hline 2 & Camelot & 3195.28 & 3196.62 & 29.50 & 86.36 & 126.83 & 73.15 & 0.6758 \\
\hline 3 & $\mathrm{Ne03490}$ & 3351.11 & 3375.95 & 30.00 & 82.97 & 118.17 & 73.00 & 0.6498 \\
\hline 4 & Wahoo & 3090.09 & 3075.57 & 29.50 & 87.63 & 123.33 & 72.15 & 0.6830 \\
\hline 5 & Goodstreak & 3203.07 & 3205.58 & 30.00 & 95.25 & 130.00 & 74.44 & 0.7047 \\
\hline 6 & Pronghorn & 3132.95 & 3124.88 & 28.50 & 93.13 & 129.50 & 72.77 & 0.7075 \\
\hline 7 & Buckskin & 2896.28 & 2852.52 & 29.50 & 99.48 & 127.50 & 74.12 & 0.7292 \\
\hline 8 & Clarkscream & 2557.34 & 2462.47 & 29.00 & 104.56 & 141.33 & 74.08 & 0.6427 \\
\hline 9 & Danby & 3156.32 & 3151.78 & 28.50 & 82.13 & 119.83 & 75.85 & 0.6453 \\
\hline 10 & Alice & 3089.12 & 3074.45 & 30.00 & 72.81 & 127.33 & 71.96 & 0.7158 \\
\hline 11 & Karl92 & 3068.67 & 3050.91 & 30.00 & 70.70 & 135.00 & 71.77 & 0.7068 \\
\hline 12 & Darrell & 2774.53 & 2712.42 & 28.50 & 89.75 & 128.50 & 73.62 & 0.7015 \\
\hline 13 & $\mathrm{Ne} 99495$ & 3270.28 & 3282.92 & 29.50 & 84.67 & 126.83 & 72.88 & 0.7053 \\
\hline 14 & Wesley & 3119.31 & 3109.19 & 28.50 & 76.20 & 128.83 & 72.75 & 0.6803 \\
\hline 15 & Alliance & 3425.14 & 3461.13 & 29.00 & 88.05 & 116.00 & 72.00 & 0.6943 \\
\hline 16 & Millennium & 3348.19 & 3372.59 & 28.00 & 89.75 & 127.17 & 73.69 & 0.6520 \\
\hline 17 & Overland & 3480.65 & 3525.02 & 30.00 & 85.94 & 121.67 & 73.48 & 0.6910 \\
\hline 18 & Expedition & 3313.13 & 3332.24 & 28.50 & 82.13 & 124.33 & 72.71 & 0.6852 \\
\hline 19 & McGill & 3400.79 & 3433.11 & 30.50 & 90.17 & 119.50 & 73.67 & 0.6982 \\
\hline 20 & NW03666 & 3457.06 & 3506.30 & 30.50 & 83.82 & 119.49 & 72.42 & 0.6532 \\
\hline 21 & NW07505 & 3360.85 & 3387.16 & 31.00 & 91.44 & 120.67 & 73.17 & 0.6883 \\
\hline 22 & NW03681 & 2969.32 & 2936.58 & 30.00 & 82.55 & 131.50 & 74.71 & 0.6623 \\
\hline 23 & NE04424 & 3155.35 & 3150.66 & 29.00 & 81.28 & 122.83 & 73.56 & 0.6102 \\
\hline 24 & NE05496 & 3241.06 & 3249.30 & 30.00 & 89.32 & 124.00 & 72.94 & 0.6475 \\
\hline 25 & NE05548 & 3357.93 & 3383.80 & 31.00 & 93.98 & 130.00 & 73.04 & 0.7140 \\
\hline 26 & NE08457 & 3391.05 & 3421.90 & 30.00 & 76.20 & 131.00 & 73.56 & 0.6375 \\
\hline 27 & NIO8708 & 3274.17 & 3287.40 & 30.50 & 80.86 & 122.67 & 71.98 & 0.6533 \\
\hline 28 & NE02558 & 3117.36 & 3106.95 & 30.00 & 88.05 & 121.67 & 72.35 & 0.6410 \\
\hline 29 & NE06545 & 3471.72 & 3523.65 & 29.50 & 84.24 & 117.17 & 71.85 & 0.6717 \\
\hline 30 & NE07444 & 3387.15 & 3417.42 & 30.50 & 89.32 & 123.67 & 72.88 & 0.6600 \\
\hline 31 & NE05425 & 3179.70 & 3178.68 & 30.00 & 86.78 & 128.49 & 72.58 & 0.6913 \\
\hline 32 & NE05430 & 3249.82 & 3259.38 & 30.50 & 90.17 & 120.89 & 73.42 & 0.6675 \\
\hline 33 & SD07165 & 3605.32 & 3668.49 & 30.50 & 84.67 & 118.49 & 73.21 & 0.6685 \\
\hline 34 & Hallam & 3165.09 & 3161.87 & 30.00 & 87.21 & 122.49 & 69.95 & 0.6508 \\
\hline 35 & Lyman & 2988.80 & 2959.00 & 30.00 & 88.90 & 136.29 & 73.59 & 0.6985 \\
\hline \multirow[t]{8}{*}{36} & NX05M41806 & 2495.98 & 2391.86 & 29.50 & 80.86 & 119.29 & 70.19 & 0.5373 \\
\hline & Var_Entry & & 69848.43 & 0.12 & 41.61 & 30.11 & 1.09 & 0.0010 \\
\hline & Var_Resid & & 63200.64 & 0.99 & 27.68 & 13.17 & 0.68 & 0.0015 \\
\hline & Gmean & & 3183.23 & 29.74 & 86.20 & 125.21 & 72.94 & 0.6716 \\
\hline & LSD & & 288.08 & 2.02 & 5.99 & 4.22 & 0.98 & 0.0438 \\
\hline & CV & & 4.59 & 3.35 & 3.52 & 1.71 & 0.68 & 3.3068 \\
\hline & Heritability & & 0.87 & 0.20 & 0.90 & 0.93 & 0.91 & 0.8084 \\
\hline & nreps & & 6 & 2 & 6 & 6 & 6 & 6 \\
\hline
\end{tabular}

genotype performance in each location was quite diverse and depended strongly of the trait under study.

We found that yield is negatively correlated with protein content and plant height. In addition, we observed that in general the genetic correlation produced the largest influence in the genotype performance, although the GE interaction was also significant and needs to be considered to avoid mistakes in selection. Therefore, the genotypes showed variation in their degree of stability from one trait to another suggesting that the genetic factors involved in the GE differed between traits (Grausgruber et al., 2000). The highly significant effects of environments and GE found in this study are in agreement with those reported by other studies (Fufa et al.,2005;Campbell et al., 2004;Peterson et al., 1992; Mengistu., 2010) conducted for winter wheat grain yield in Nebraska.

The best genotypes for grain yield across the three environments weregenotypes NW03666, SD07165, 
NE06545 and Overland. It is important to point out that only the line Overland was released, the other three were experimental lines. For NDVI the best genotypes are: Lyman and Buckskin, both were released. For GVW the best genotypes are: Lyman, NW03681, Danby and Goodstreak, only line NW03681 is experimental. For Adate all genotypes are similar. The best genotypes for plant height were: Goodstreak, Buckskin and Clarkscream, all released. For protein content the best gwwwenotypes are: Goodstreak, Karl92, Lyman, and Clarkscream, all released. While the worst genotypes are: Hatcher, NE03490 and Clarkscream (for yield), NX05M41806 (for NDVI), Hallam and NX05M41806 (for GVW), Karl 92, Alice and Wesley (for height) and Alliance, NX05M41806, Danby and NE02558 (for protein content). In general the average yield of the experimental lines were better than the released lines which is to be expected due to the released lines including older lines and breeding progress should occur. For Adate, the performance was the same between experimental and released lines which is expected because selecting for adaptation in Nebraska means that there is an optimum Adate and both release and experimental lines select for that Adate. However, for NDVI, height, GVW and protein, the average performance of the experimental lines was lower than the released lines. Also, it is important to point out that we found a negative correlation between grain yield and protein content, and between yield and plant height.

\section{CONCLUSIONS}

We found that in general the average grain yield of the experimental lines were better than the released lines. The best genotypes for grain yield across the three environments are genotypes NW03666, SD07165, NE07444 and Overland. For vegetation index the best lines were: Lyman and Buckskin. For grain volume weight the best lines were: Lyman, NW03681, Danby and Goodstreak. For anthesis date all genotypes were similar. For plant height, the best lines were Goodstreak, Buckskin and Clarkscream. For protein content, the best lines were Goodstreak, Karl92, Lyman, and Clarkscream. For anthesis date, the performance was similar between experimental and released lines. However, for vegetation index, plant height, grain volume weight and protein content, the average performance of the experimental lines was lower than the released lines. Also, it is important to point out that the linear mixed models and site regression model implemented were very effective for reaching the objectives of the present research.

\section{Authors' contributions}

Richard S. Little and P. Sephen Baensiger conducted the experiments and collected the data. Osval Antonio
Montesinos-López, Eliel Martínez-Crúz and Emeterio Franco-Pérez did the analysis and write the paper and we work all approximately the same amount of time.

\section{REFERENCES}

Allard, R. W. and A. D. Bradshaw. 1964. Implications of genotypeenvironmental interactions in applied plant breeding. Crop Sci. 4: 503-508.

Baenziger, P. S., I. Salah, R. S. Little, D. K. Santra, T. Regassa, and M. Y. Wang. 2011. Structuring an efficient organic wheat breeding program. Sustainability. 3: 1190-1205.

Basford, K. E. and M. Cooper. 1998. Genotype x environment interactions and some considerations of their implications for wheat breeding in Australia. Aust. J. Agric. Res. 49: 153-174.

Campbell, B. T., P. S. Baenziger, K. M. Eskridge, H. Budak, N. A. Streck, A. Weiss, K. S. Gill and M. Erayma. 2004. Using environmental covariates to explain genotypexenvironment and QTLxenvironment interactions for agronomic traits on chromosome 3A of wheat. Crop Sci. 44: 620-627.

Cooper, M. and I. DeLacy. 1994. Relationships among analytical methods used to study genotypic variation and genotype-byenvironment interaction in plant breeding multi-environment experiments. Theor. Appl. Genet. 88(5): 561-572.

Crossa, J., P. L. Cornelius and W. Yan. 2002. Biplots of linearbilinear models for studying crossover genotype_environment interaction. Crop Sci. 42: 619-633.

Crossa, J. and P. L. Cornelius. 1997. Site regression and shifted multiplicative models clustering of cultivar trials sites under heterogeneity of error variances. Crop Sci. 37: 406-415.

Denčić, S., N. Mladenov and B. Kobiljski. 2011. Effects of genotype and environment on breadmaking quality in wheat. Int. J. Plant Prod. 5: 71-82.

Fufa, H., P. S. Baenziger, B. S. Beecher, R. A. Graybosch, K. M. Elkridge and L. A. Nelson. 2005. Genetic improvement trends in agronomic performances and end-use quality characteristics among hard red winter wheat cultivars in Nebraska. Euphytica. 144: 187-198.

Grausgruber, H., M. Oberforster, M. Werteker, P. Ruckenbauer and J. Vollmann. 2000. Stability of quality in Austrean grown winter wheats. Field Crops Res. 66: 257-267.

Hildermann, I., A. Thommen, D. Dubois, A. Wiemken, T. Boller and P. Maeder. 2008. Response of Old, New and Organically Bred Winter Wheat Cultivars in Different Farming Systems: Concept and Experimental Layout in the Dok Field Trial. Poster at: Cultivating the Future Based on Science: $2^{\text {nd }}$ Conference of the International Society of Organic Agriculture Research ISOFAR, Modena, Italy, pp. 18-20.

Holland, J. B. 2006. Estimating genotypic correlations and their standard errors using multivariate restricted maximum likelihood estimation with SAS Proc MIXED. Crop Sci. 46: 642-654.

Marinciu, C. and N. N. Saulescu. 2009. Grain yield and protein concentration in winter wheat cultivars tested with and without nitrogen fertilizer. Rom. Agric. Res. 27: 69-81.

Mengistu, N., P. S. Baenziger, L. A. Nelson, K. M. Eskridge, R. N. Klein, D. D. Baltensperger and R. W. Elmore. 2010. Grain yield performance and stability of cultivar blends vs. component cultivars of hard winter wheat in Nebraska. Crop Sci. 50: 617-623.

Peterson, C. J., R. A. Graybosch, P. S. Baenziger and A. W. Grombacher. 1992. Genotype and environment effects on quality characteristics of hard red winter wheat. Crop Sci. 32: 98-103. 
SAS. 2003. SAS ® 9.1 for Windows. SAS Institute Inc., Cary, NC.

Taghouti, M., F. Gabou, N. Nsarellah, R. Rhrib, M. El-Haila, M. Kamar, F. Abbad-Andaloussi and S. M. Udupa. 2010. Genotype x environment interaction for quality traits in durum wheat cultivars adapted to different environments. Afr. J. Biotechnol. 9(21): 3054-3062.

Trethowan, R. and J. Crossa. 2007. Lessons learnt from forty years of international spring bread wheat trials. Euphytica. 157: 385-390.
Yan, W. and L. A. Hunt. 1998. Genotype by environment interaction and crop yield. Plant Breed. Rev. 16: 135-178.

Yan, W., P. L. Cornelius, J. Crossa and L. A. Hunt. 2001. Comparison of two types of GGE biplots for studying genotype by environment interaction. Crop Sci. 41: 656-663.

Yan, W., M. S. Kang, B. Ma, S. Woods and P. L. Cornelius. 2007. GGE biplot vs. AMMI analysis of genotype-by-environment data. Crop Sci. 47(2): 643-653. 